\title{
Necessity for a Significant Maintenance Dosage Reduction of Voriconazole in Patients with Severe Liver Cirrhosis (Child-Pugh Class C)
}

\author{
Takehiro Yamada, ${ }^{a}$ Shungo Imai, ${ }^{a}$ Yasuyuki Koshizuka, ${ }^{b}$ Yuki Tazawa, ${ }^{a}$ Keisuke Kagami, ${ }^{a}$ \\ Naoki Tomiyama, ${ }^{a}$ Ryosuke Sugawara, ${ }^{a}$ Akira Yamagami, ${ }^{a}$ Tsuyoshi Shimamura, ${ }^{c}$ and \\ Ken Iseki*,a,d \\ ${ }^{a}$ Department of Pharmacy, Hokkaido University Hospital; Kita 14-jo, Nishi 5-chome, Kita-ku, Sapporo 060-8648, \\ Japan: ${ }^{b}$ Department of Gastroenterological Surgery I, Hokkaido University Graduate School of Medicine; Kita \\ 15-jo, Nishi 7-chome, Kita-ku, Sapporo 060-8638, Japan: ${ }^{c}$ Division of Organ Transplantation, Hokkaido University \\ Hospital; Kita 14-jo, Nishi 5-chome, Kita-ku, Sapporo 060-8648, Japan: and ${ }^{d}$ Division of Pharmasciences, Faculty \\ of Pharmaceutical Sciences, Laboratory of Clinical Pharmaceutics and Therapeutics; Hokkaido University; Kita \\ 12-jo, Nishi 6-chome, Kita-ku, Sapporo 060-0812, Japan. \\ Received February 27, 2018; accepted April 26, 2018; advance publication released online May 11, 2018
}

Therapeutic drug monitoring for voriconazole, an antifungal agent, is essential for maximizing efficacy and preventing toxicity. The aim of this study was to elucidate the optimal maintenance dose of voriconazole in patients with severe liver cirrhosis (Child-Pugh class $C$ ) by reviewing the plasma trough concentrations obtained by therapeutic drug monitoring and daily doses of voriconazole. We retrospectively evaluated 6 patients with Child-Pugh class $C$ cirrhosis who received oral voriconazole treatment and were liver transplant recipients or were awaiting liver transplantation. We compared their voriconazole trough concentrations and daily maintenance doses to those of patients who did not have liver cirrhosis $(n=56)$. We found that plasma voriconazole trough concentrations in all patients with Child-Pugh class $C$ were almost within therapeutic range, and the median plasma trough concentration at steady state was not significantly different from that of patients who did not have liver cirrhosis. In addition, the median daily maintenance dose of voriconazole was significantly lower $(2.13 \mathrm{mg} / \mathrm{kg} / \mathrm{d})$ than that of the control patients $(6.27 \mathrm{mg} / \mathrm{kg} / \mathrm{d})$, suggesting that trough voriconazole concentrations are elevated in Child-Pugh class $C$ patients. Thus, we conclude that oral voriconazole maintenance doses in patients with Child-Pugh class $\mathrm{C}$ should be reduced to approximately one-third that of patients with normal liver function, with the follow-up dose adjusted by therapeutic drug monitoring.

Key words voriconazole; therapeutic drug monitoring; Child-Pugh class C

Voriconazole (VRCZ) is a broad-spectrum triazole antifungal agent that acts against clinically significant fungal pathogens. It is primarily metabolized by the liver microsomal enzyme CYP2C19 or CYP3A4. ${ }^{1-4)}$ Thus, a large number of inter- and intra-individual variations in $\mathrm{VRCZ}$ pharmacokinetics (PK) are attributable to liver disorders, concomitant use of CYP 2C19/3A4 inducers or inhibitors, CYP2C19 genetic polymorphisms, and food intake. ${ }^{2,5,6)}$ Although some studies have highlighted an association between VRCZ plasma concentrations and successful clinical treatment of fungal infections, excessive exposure to $\mathrm{VRCZ}$ enhances the possibility of severe adverse drug reactions ${ }^{5-8}$ Hence, therapeutic drug monitoring (TDM) is recommended for the appropriate use of VRCZ. ${ }^{6,9)}$

Liver cirrhosis is an advanced liver disease that decreases immune function and increases intestinal permeability, causing patients to become susceptible to pathogens (e.g., fungi). Because VRCZ is primarily metabolized in the liver, the dose of VRCZ should be adjusted based on the severity of the liver disorder. The Japanese practice guidelines recommend a target VRCZ trough level as $\geq 1.0-2.0 \mathrm{mg} / \mathrm{L}$ to maintain clinical efficacy. Caution is recommended when trough levels exceed 4.0-5.0 mg/L. Thus, the target VRCZ plasma trough concentrations should be set at $1.0-5.0 \mathrm{mg} / \mathrm{L}$. $\left.{ }^{9}\right)$ To achieve that, the VRCZ package insert recommends reducing the maintenance dose by $50 \%$ in patients with mild (Child-Pugh class A) to moderate (Child-Pugh class B) hepatic insufficiency. ${ }^{10)}$ How- ever, for patients with more severe liver cirrhosis (Child-Pugh class C), no optimal dose indication or information exists.

To the best of our knowledge, only one case report has been published on VRCZ pharmacokinetics in a patient with ChildPugh class $\mathrm{C}$ (Child-Pugh C). The patient had been administered the standard maintenance dose $(2 \mathrm{mg} / \mathrm{kg}$ twice daily for patients with normal liver function per the VRCZ package insert), which resulted in toxic plasma levels that caused unconsciousness, leading to admission to the intensive care unit., ${ }^{911}$

To date, no studies have evaluated the maintenance of target VRCZ trough concentrations in patients with Child-Pugh $\mathrm{C}$, and the maintenance dose required to attain target trough concentrations in patients with severe hepatic dysfunction remains unknown.

For liver transplant recipients, deep-seated fungal infections, such as invasive aspergillosis (IA), are among the most serious, life-threatening complications. ${ }^{12}$ Liver cirrhosis is also a risk factor for IA. ${ }^{13,14)}$ Hence, prophylactic or targeted therapy for fungal infection is an important strategy in the management of liver transplant recipients. ${ }^{12,15)}$ Prophylactic VRCZ is reportedly safe and clinically effective in high-risk liver transplant recipients, and is associated with a high probability of survival from IA. ${ }^{12,15)}$

We retrospectively reviewed the maintenance dose and plasma trough concentrations of VRCZ in patients with ChildPugh C, and compared their profiles to those of patients who did not have liver cirrhosis in order to determine the optimal 
maintenance dose for VRCZ. To the best of our knowledge, this is the first report on TDM-based optimization of VRCZ maintenance dose in patients with Child-Pugh C.

\section{PATIENTS AND METHODS}

Patients This single-center, retrospective study was conducted at Hokkaido University Hospital, Sapporo, Japan. We reviewed medical records from the charts of patients (aged 18 years or older) who had received oral VRCZ. Patients whose VRCZ plasma trough concentrations had been measured between 2012 and 2016 were considered eligible for inclusion in this study. Those who had concomitantly received rifampicin, rifabutin, carbamazepine, phenytoin, and anti-human immunodeficiency virus drugs were excluded from the study. We also excluded patients who had been administered VRCZ injections, even if it was only a single injection.

In addition, we assessed patients who did not have liver cirrhosis as a comparative control (non-liver cirrhosis; non-LC) group $(n=56)$. Patients who had severe hepatic dysfunction (total bilirubin $>2.0 \mathrm{mg} / \mathrm{dL}$ ) were excluded from the non-LC group.

Patients' medical records were individually reviewed to collect clinical information, including underlying diseases, laboratory data, adverse events, VRCZ dosing, and concomitant medications taken during VRCZ treatment. Their $\beta$-D-glucan serum level (normal $<11.0 \mathrm{pg} / \mathrm{mL}$ ) were determined by chromogenic assay using Wako $\beta$-glucan tests (Wako Pure Chemical Industries, Ltd., Japan), and Aspergillus antigen were determined by enzyme immunoassay using Platelia Aspergillus Ag (Bio-Rad Labs, U.S.A.). We also investigated the impact of the concomitant use of glucocorticoids and proton-pump inhibitors (PPIs), as these medications may affect VRCZ pharmacokinetics. ${ }^{16-20)}$

Plasma VRCZ Determinations TDM using VRCZ plasma concentration was performed as part of routine clinical practice at Hokkaido University Hospital. We collected blood samples within $30 \mathrm{~min}$ before the next dose to determine trough concentration, and the dosage of VRCZ was adjusted on the basis of those results.

All patients were administered VRCZ twice daily. Plasma VRCZ levels were determined using HPLC and UV detection
$(250 \mathrm{~nm})$ by modifying a previously established method. ${ }^{21)}$ In brief, $100 \mu \mathrm{L}$ of plasma was spiked with $100 \mu \mathrm{L}$ of VRCZ (Sigma-Aldrich Japan, Tokyo, Japan) working solution $(0.25,0.50$, $1.00,2.00,5.00$, and $10.0 \mathrm{mg} / \mathrm{L}$ in methanol), and $100 \mu \mathrm{L}$ of $5 \mathrm{mg} / \mathrm{L}$ ethylparaben (Sigma-Aldrich Japan) in methanol was used as the internal standard. The plasma samples were mixed with equal volumes of methanol rather than VRCZ working solution. We collected the supernatant after centrifugation at $15000 \mathrm{rpm}$ for $15 \mathrm{~min}$. Aliquots of the supernatant $(50 \mu \mathrm{L})$ were analyzed by an HPLC system (LC-10ADVP; Shimadzu, Kyoto, Japan) equipped with a UV detection system at $253 \mathrm{~nm}$ and a reversed-phase $\mathrm{C} 8$ packed column (NUCLEOSIL 100-5C8, 4.6×250 mm; GL Sciences, Tokyo, Japan). The mobile phase consisted of phosphate $(60 \mathrm{~mm})$ buffer and methanol $(1: 1, \mathrm{v} / \mathrm{v})$, at a flow rate of $1.0 \mathrm{~mL} / \mathrm{min}$, and the column oven was set at $50^{\circ} \mathrm{C}$. The analytical measurement range was $0.5-10 \mathrm{mg} / \mathrm{L}$. The intra-day assay coefficient of variations (CVs) of $0.5,2.0$, and $10 \mathrm{mg} / \mathrm{L} \mathrm{VRCZ} \mathrm{were} 2.53,3.29$, and $2.96 \%$, respectively $(n=6)$, and the inter-day assay CVs of 0.5 , 2.0 , and $10 \mathrm{mg} / \mathrm{L} \mathrm{VRCZ} \mathrm{were} 4.15,3.30$, and $0.39 \%$, respectively $(n=6)$. The relative errors of intra-day assays $(n=6)$ of $0.5,2.0$, and $10 \mathrm{mg} / \mathrm{L} \mathrm{VRCZ} \mathrm{were} 0.00,1.92$, and $0.58 \%$; and those for inter-day assays $(n=6)$ were $6.17,1.20$, and $0.55 \%$, respectively.

Comparative Analysis of Non-LC and Child-Pugh C Patients We compared the trough plasma concentration at steady state, daily maintenance dose $(\mathrm{mg} / \mathrm{kg} / \mathrm{d})$, and concentration to dose (C:D) ratio of VRCZ of the non-LC and ChildPugh $\mathrm{C}$ groups. All patients with Child-Pugh $\mathrm{C}$ were awaiting or had received liver transplants (Table 1). Eight patients had Child-Pugh C, of whom one was excluded because parenteral VRCZ was initially administered, and another was excluded because the duration was too short $(12 \mathrm{~d}$ on VRCZ therapy with trough VRCZ concentrations obtained only on Days 4 and 9) to evaluate the VRCZ steady state plasma trough level. Of the evaluable VRCZ plasma concentrations, 56 patients in the non-LC group had 56 sampling points, and 6 patients in the Child-Pugh $\mathrm{C}$ group had 6 sampling points. For the nonLC group, plasma trough concentrations just before dosing on Day 5 or later were used for analysis.

The plasma half-life of VRCZ in Child-Pugh C patients is reportedly $53.1 \mathrm{~h} .{ }^{11)}$ On the basis of this information, we de-

Table 1. Clinical Backgrounds of Patients with Child-Pugh Class C

\begin{tabular}{|c|c|c|c|c|c|c|c|c|}
\hline No. & $\begin{array}{c}\text { Gender } \\
\text { (age in years) } \\
\text { Body weight }\end{array}$ & $\begin{array}{l}\text { Child-Pugh } \\
\text { score }\end{array}$ & $\begin{array}{c}\text { Underlying disease } \\
\text { (cause of liver transplantation) }\end{array}$ & $\begin{array}{l}\text { Indication for } \\
\text { VRCZ therapy }\end{array}$ & $\begin{array}{c}\text { Antifungal } \\
\text { treatment } \\
\text { prior to VRCZ }\end{array}$ & $\begin{array}{c}\text { Baseline } \\
\beta \text {-D-glucan } \\
(\mathrm{pg} / \mathrm{mL})\end{array}$ & $\begin{array}{c}\text { Baseline } \\
\text { Aspergillus } \\
\text { antigen }\end{array}$ & $\begin{array}{l}\text { Fungus } \\
\text { cultured* }\end{array}$ \\
\hline 1 & $\begin{array}{l}\mathrm{F}(64) \\
47.8 \mathrm{~kg}\end{array}$ & 10 & $\begin{array}{l}\text { Fulminant hepatitis } \\
\text { (15 y after living-donor transplantation) }\end{array}$ & $\begin{array}{l}\text { Empiric therapy } \\
\text { (sinus mycosis) }\end{array}$ & $\begin{array}{c}\text { MCFG } \\
50 \mathrm{mg} \mathrm{q} 24 \mathrm{~h}\end{array}$ & 11.2 & + & $\begin{array}{l}\text { C. glabrata } \\
\text { (feces) }\end{array}$ \\
\hline 2 & $\begin{array}{l}\mathrm{M}(48) \\
62.7 \mathrm{~kg}\end{array}$ & 11 & $\begin{array}{l}\text { PBC } \\
\text { (9 y after living-donor transplantation) }\end{array}$ & Empiric therapy & - & $<6.0$ & + & Not determined \\
\hline 3 & $\begin{array}{l}M(64) \\
67.5 \mathrm{~kg}\end{array}$ & 10 & $\begin{array}{l}\text { SBC } \\
\text { (pretransplantation) }\end{array}$ & $\begin{array}{c}\text { Empiric therapy } \\
\text { (Aspergillus infection) }\end{array}$ & $\begin{array}{c}\text { MCFG } \\
50 \mathrm{mg} \mathrm{q} 24 \mathrm{~h}\end{array}$ & 14.3 & + & $\begin{array}{c}\text { C. albicans } \\
\text { (sputum, feces) }\end{array}$ \\
\hline 4 & $\begin{array}{l}\mathrm{F}(58) \\
57.9 \mathrm{~kg}\end{array}$ & 11 & $\begin{array}{l}\text { LC-alcoholic } \\
\text { (pretransplantation) }\end{array}$ & $\begin{array}{l}\text { Antifungal prophy- } \\
\text { laxis }\end{array}$ & $\begin{array}{c}\mathrm{MCFG} \\
50 \mathrm{mg} \mathrm{q} 24 \mathrm{~h}\end{array}$ & $<6.0$ & - & $\begin{array}{l}\text { C. albicans } \\
\text { (feces) }\end{array}$ \\
\hline 5 & $\begin{array}{l}M(59) \\
57.1 \mathrm{~kg}\end{array}$ & 13 & $\begin{array}{l}\text { PSC } \\
\text { (pretransplantation) }\end{array}$ & Empiric therapy & - & 12.1 & + & $\begin{array}{l}\text { C. albicans } \\
\text { (feces) }\end{array}$ \\
\hline 6 & $\begin{array}{l}\mathrm{F}(64) \\
55.2 \mathrm{~kg}\end{array}$ & 10 & $\begin{array}{l}\text { HCV-cirrhosis } \\
\text { (pretransplantation) }\end{array}$ & $\begin{array}{l}\text { Antifungal prophy- } \\
\text { laxis }\end{array}$ & - & $<6.0$ & + & Negative \\
\hline
\end{tabular}

VRCZ, voriconazole; MCFG, micafungin; q24h, every $24 \mathrm{~h}$; PBC, primary biliary cirrhosis; SBC, secondary biliary cirrhosis; LC, liver cirrhosis; PSC, primary sclerosing cholangitis; HCV, hepatitis C virus. * Samples for surveillance cultures were collected before initiating VRCZ treatment. 
termined that the number of days to reach the plasma steady state in Child-Pugh $\mathrm{C}$ patients was $10 \mathrm{~d}$ after initiation of therapy. Thus, for the Child-Pugh $\mathrm{C}$ patients in whom no dosage change occurred after the loading dose, plasma trough concentrations after Day 10 were used for analysis. When the maintenance dose varied, we utilized the trough levels $10 \mathrm{~d}$ from the date of the last dosage change. Although by applying these criteria, we have 28 points from six patients with ChildPugh class C cirrhosis, we also used the first trough after reaching steady state in these patients (Figs. 2, 3) because the difference between the non-LC group did not change with the use of six points (one point by one patient) or 28 points from that of the Child-Pugh C group.

Statistical Analysis Data are presented as the median and interquartile range (IQR). Differences between groups were analyzed by the Mann-Whitney $U$-test or Fisher's exact test. All statistical analyses were performed using Prism 6 (GraphPad Software, San Diego, CA, U.S.A.). We considered $p<0.05$ to be statistically significant.

Ethics This study was conducted in accordance with the Declaration of Helsinki and its amendments. The study protocol was approved by the ethics committee of the Hokkaido University Hospital (protocol number: 016-0155).

\section{RESULTS}

Clinical Course of Patients with Child-Pugh C Six patients diagnosed with Child-Pugh $\mathrm{C}$ were eligible for inclusion in this study (Table 1). Of those patient cases, Patients 1 and 2 had received liver transplants 15 and 9 years prior to VRCZ therapy, respectively (Table 1). The remaining four patients (3-6) were awaiting liver transplantation. Their Child-Pugh scores ranged from 10 to 13 at the beginning of $\mathrm{VRCZ}$ treatment. The baseline C-reactive protein (CRP) levels for patients with Child-Pugh $\mathrm{C}$ ranged between 0.12 and $5.86 \mathrm{mg} / \mathrm{dL}$. Although 5 patients tested positive for Aspergillus antigen at the baseline, 4 of them tested negative at the conclusion of VRCZ treatment. In those 4 patients, fungus was initially detected in the feces or sputum by surveillance culture (Table 1), but no fungus was detected at the end of VRCZ treatment. In addition, $\beta$-D-glucan was not detected in 3 patients at initiation of VRCZ treatment. No adverse drug reactions, including hepatotoxicity, were attributed to VRCZ treatment in any of the 6 patients with Child-Pugh C.

Table 2 summarizes the VRCZ dose, plasma VRCZ concentrations, and factors that possibly affect VRCZ pharmacoki- netics, such as renal replacement therapy and coadministration of glucocorticoids/PPIs. Patients 2 and 3 began VRCZ treatment with loading doses equivalent to those of patients with normal liver function. The remaining 4 patients began treatment with much lower doses. The TDM practice guidelines recommend beginning TDM 5 to $7 \mathrm{~d}$ after initiation of $\mathrm{VRCZ}$ treatment. However, TDM was performed much earlier (Day 3 or 4 ) in 4 of the 6 patients (Patients 1, 3, 4, and 5) because of severe liver cirrhosis. The VRCZ maintenance dose ranged from 50 to $200 \mathrm{mg} / \mathrm{d}$ (Table 2).

The clinical courses of Patient 1 (Fig. 1A) and Patient 3 (Fig. 1B), which we consider representative cases, are described below in detail.

Patient 1 A 64-year-old female had received a livingdonor liver transplant 15 years prior to VRCZ treatment because of drug-induced (suspected rifampicin-induced) fulminant hepatitis. The patient was admitted for recurrent liver cirrhosis-induced hepatic encephalopathy with right maxillary sinus mycosis. Voriconazole was initiated for pre- and postoperative therapy after the surgery for sinus mycosis.

The treatment began at $100 \mathrm{mg}$ of $\mathrm{VRCZ}$ orally twice on the first day (200mg on Day 1; Table 2, Fig. 1). From Day 2 and onward, VRCZ was lowered to a maintenance dose of $50 \mathrm{mg}$ twice daily (total of $100 \mathrm{mg}$ per day; $2.11 \mathrm{mg} / \mathrm{kg} / \mathrm{d}$ ) from Days 2 to 17. The first VRCZ trough concentration was obtained on Day $3(1.18 \mathrm{mg} / \mathrm{L})$. On Day 6, a surgical operation for sinus mycosis was performed. On Day 13, the plasma VRCZ concentration reached $3.32 \mathrm{mg} / \mathrm{L}$, and the C:D ratio was estimated at 1.57 (Table 2). The trough plasma concentration of VRCZ gradually increased to $3.52 \mathrm{mg} / \mathrm{L}$ on Day 17 , signifying the need for a more significant dose reduction. After Day 18, the VRCZ dose was reduced to $25 \mathrm{mg}$ twice daily (total of $50 \mathrm{mg}$ per day) based on the results from TDM. At the beginning of VRCZ therapy, Candida glabrata was detected in the feces by surveillance culture. However, C. glabrata was undetectable at the end of therapy. Two months after the completion of VRCZ treatment, the patient was discharged (Fig. 1A).

Patient 3 Patient 3 was admitted for liver transplantation because of liver failure from secondary biliary cirrhosis due to chronic cholangitis. The treatment began with VRCZ as empiric therapy for an Aspergillus infection. The VRCZ dose was initially $300 \mathrm{mg}$ twice (total $600 \mathrm{mg}$ ) on the first day of treatment, then shifted to a maintenance dose of $75 \mathrm{mg}$ twice daily (total of $150 \mathrm{mg}$ per day) on Days 2 and 3. The plasma trough concentration of $\mathrm{VRCZ}$ was $4.20 \mathrm{mg} / \mathrm{L}(\mathrm{C}: \mathrm{D}=1.89)$ on Day 3 (just before the fifth dose). On the basis of this result,

Table 2. Voriconazole Plasma Concentration in Patients with Child-Pugh Class C during the First 30 Days of Treatment

\begin{tabular}{|c|c|c|c|c|c|c|c|c|c|}
\hline \multirow{2}{*}{$\begin{array}{l}\text { Case } \\
\text { No. }\end{array}$} & \multicolumn{2}{|c|}{ VRCZ daily dosage $(\mathrm{mg} / \mathrm{d})$} & \multicolumn{4}{|c|}{ Plasma VRCZ trough concentration (mg/L) (day sample was taken) } & \multirow{2}{*}{$\begin{array}{l}\text { Renal replacement } \\
\text { therapy and/or } \\
\text { plasma exchange }\end{array}$} & \multicolumn{2}{|c|}{ Concomitant drugs } \\
\hline & Day 1 & Maintenance dose & Days 3, 4 (day) & Days 5-9 (day) & Days $10-14$ (day) & Days $15-30$ (day) & & Glucocorticoids & PPIs \\
\hline 1 & 200 & $50-100$ & $1.18(3)$ & $2.45(8)$ & $3.32(13)$ & $3.52(17)$ & - & PDN (p.o.) & - \\
\hline 2 & 600 & 200 & - & $2.40(5)$ & $2.49(11)$ & $2.15(19)$ & - & $\begin{array}{c}3.0 \mathrm{mg} / \mathrm{d} \\
\text { PDN (p.o.) } \\
2.5 \mathrm{mg} / \mathrm{d}\end{array}$ & Rabeprazole \\
\hline 3 & 600 & $100-200$ & $4.20(3)$ & $3.09(8)$ & $2.51(12)$ & $2.14(15)$ & - & - & Esomeprazole \\
\hline 4 & 50 & $100-200$ & $1.61(4)$ & $2.34(9)$ & $2.43(13)$ & $2.55(20)$ & HD, HDF, PE & - & Rabeprazole \\
\hline 5 & 100 & $100-150$ & $0.85(3)$ & $1.24(5) 1.43(9)$ & - & $0.91(16)$ & HD, PE & - & Rabeprazole \\
\hline 6 & 300 & $100-200$ & - & - & $4.61(11)$ & $6.55(17)$ & - & - & - \\
\hline
\end{tabular}

VRCZ, voriconazole; PPI, proton pump inhibitor; PDN, prednisolone; po, orally; HD, hemodialysis; HDF, hemodiafiltration; PE, plasma exchange. 

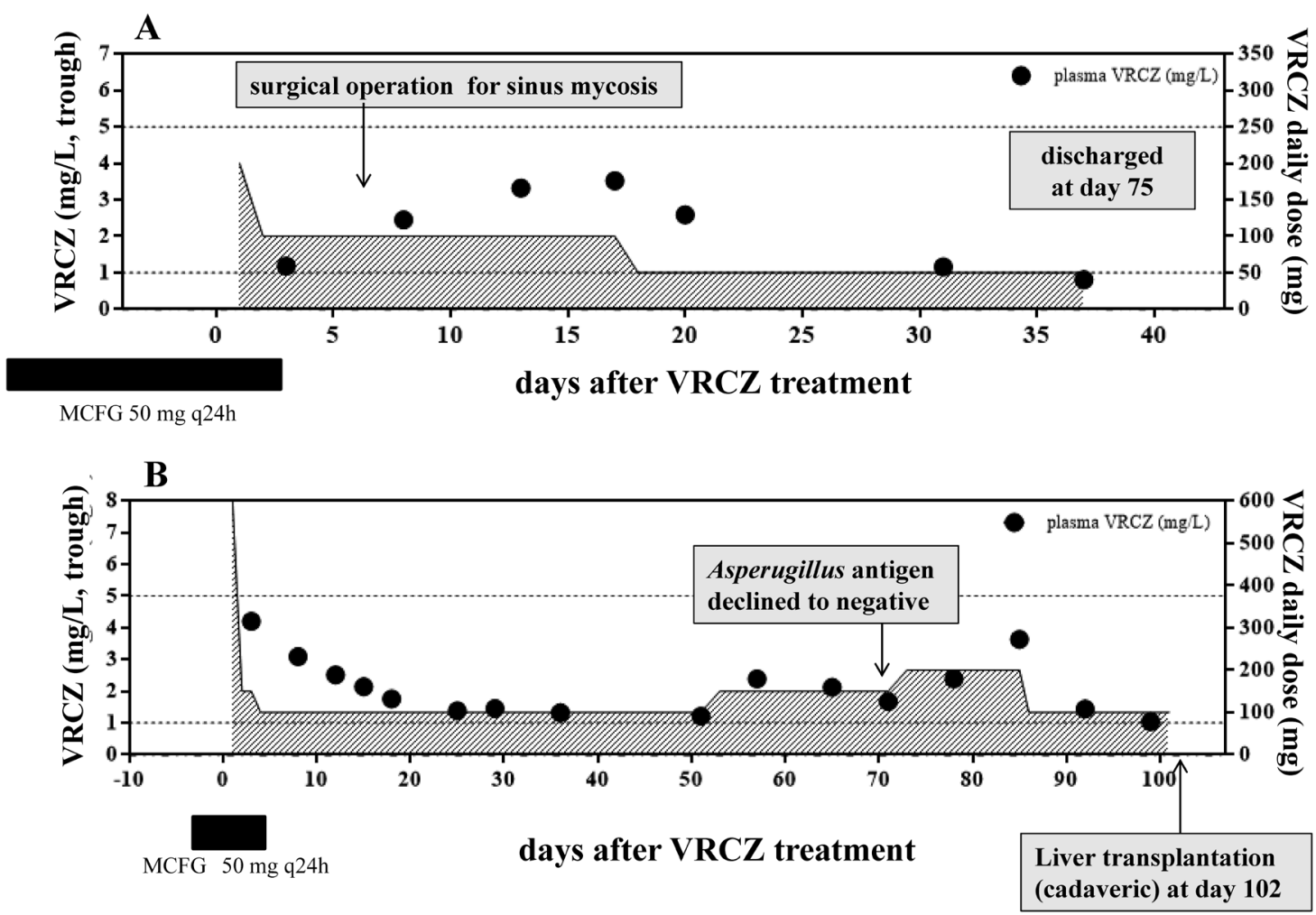

Fig. 1. The Clinical Course of VRCZ Therapy in Two Representative Child-Pugh C Patients

$x$-Axis: VRCZ treatment duration; left $y$-axis: plasma concentration of VRCZ (trough); right $y$-axis: dosage (mg/d) of VRCZ; closed circles: trough plasma concentrations of VRCZ; grayed areas: dosage $(\mathrm{mg} / \mathrm{d})$ of VRCZ. Patients 1 and 3 in this graph correspond to A and B, respectively.

Table 3. Comparison of Baseline Characteristics (Including Laboratory Data) between the Non-LC Control Group and the Child-Pugh C Group

\begin{tabular}{|c|c|c|}
\hline Patient characteristics & Non-LC control & Child-Pugh C \\
\hline Number of patients (male/female) & $56(39 / 17)$ & $6(3 / 3)$ \\
\hline Age (years) ${ }^{\dagger}$ & $57.5(38.5,70.0)$ & $61.0(55.5,64.0)$ \\
\hline Body weight $(\mathrm{kg})^{\dagger}$ & $52.9(44.2,64.6)$ & $58.6(53.7,64.0)$ \\
\hline $\operatorname{AST}(\mathrm{IU} / \mathrm{L})^{\dagger}$ & $27.0(19.3,39.0)$ & $44.0(27.5,60.5)$ \\
\hline $\operatorname{ALT}(\mathrm{IU} / \mathrm{L})^{\dagger}$ & $27.0(15.0,51.0)$ & $23.5(9.00,42.8)$ \\
\hline Serum albumin $(\mathrm{mg} / \mathrm{dL})^{\dagger}$ & $3.00(2.60,3.50)^{\#}$ & $3.25(2.85,3.38)$ \\
\hline Total bilirubin $(\mathrm{mg} / \mathrm{dL})^{\dagger}$ & $0.600(0.400,1.00)^{\#}$ & $14.5(4.73,29.0)^{*}$ \\
\hline $\mathrm{CRP}(\mathrm{mg} / \mathrm{dL})^{\dagger}$ & $1.41(0.240,4.79)^{\#}$ & $0.37(0.165,3.78)$ \\
\hline Concomitant use of glucocorticoid & 25 & 2 \\
\hline Concomitant use of PPIs & 32 & 4 \\
\hline Patients on renal replacement therapy or PE & 6 & 2 \\
\hline
\end{tabular}

LC, liver cirrhosis; Child-Pugh C, Child-Pugh class C; AST, aspartate transaminase; ALT, alanine transaminase; CRP, C-reactive protein; PPI, proton pump inhibitor; PE, plasma exchange. ${ }^{\#} n=55$; ${ }^{\dagger}$ Data expressed as the median (interquartile range). ${ }^{*} p<0.05$, significantly different from the non-LC control group (Mann-Whitney $U$-test).

the maintenance dose of VRCZ was reduced to $50 \mathrm{mg}$ twice daily. On Day 15, the trough level of VRCZ was $2.14 \mathrm{mg} / \mathrm{L}$. The duration of VRCZ therapy was $101 \mathrm{~d}$, and almost all the VRCZ trough levels were maintained within therapeutic range $(1.0-5.0 \mathrm{mg} / \mathrm{L})$. At the beginning of the therapy, the patient tested positive for Aspergillus antigen, which resolved by the end of treatment. Similarly, fungus (Candida albicans) detected in the feces and sputum at the baseline of VRCZ therapy was not detectable at the end of the therapy. On Day 102, the patient underwent successful liver transplantation (Fig. 1B).

Comparative Study of Child-Pugh C vs. Non-LC Patients We analyzed 54 sampling points from 6 patients with Child-Pugh C, of which 50 points $(92.6 \%)$ were within the VRCZ trough target range $(1.0-5.0 \mathrm{mg} / \mathrm{L})$. Table 3 presents the baseline characteristics of the Child-Pugh C (Child-C) group $(n=6)$, with the non-LC group as a comparative control $(n=56)$. In the non-LC group, 30 of the 56 patients were on hematology medicine, and 5 were on respiratory medicine.

Among the baseline characteristics, only total bilirubin was significantly higher in the Child-Pugh $\mathrm{C}$ group than in the non-LC control group (Table 3), reflecting the pathophysiological condition of severe liver cirrhosis. Figure 2A shows the median VRCZ plasma trough concentrations at steady state for both groups. Although the median VRCZ trough concentration was not significantly different between groups, the C:D ratio was significantly higher in the Child-Pugh $\mathrm{C}$ group (Fig. 2B) than in the non-LC group. In contrast, the median VRCZ maintenance dose for the Child-Pugh C group $(2.13 \mathrm{mg} / \mathrm{kg} / \mathrm{d})$ 
A

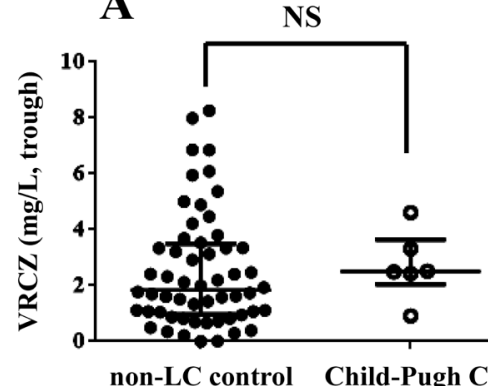

median

(IQR)
1.85

(0.975-3.49)

\subsection{0}

(2.05-3.64)

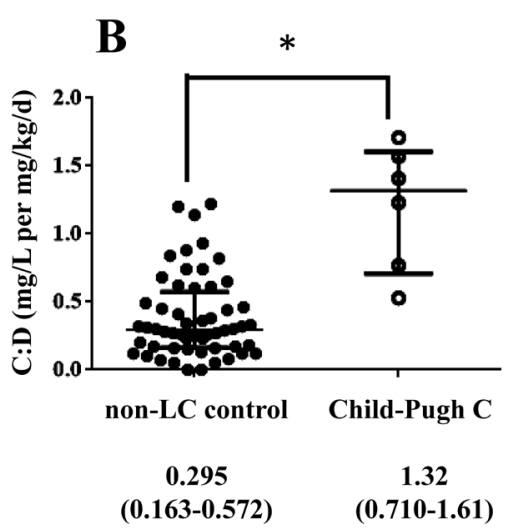

Fig. 2. A Comparison of the Plasma Trough Concentrations (A) and the C:D Ratio (B) of VRCZ between the Non-LC Group and Child-Pugh C Groups

The non-LC group consisted of patients who were not diagnosed with liver cirrhosis (56 patients, 56 sample points). The plasma VRCZ trough concentrations were obtained after reaching their steady state during oral VRCZ treatment. The C:D ratio $(\mathrm{mg} / \mathrm{L}$ per $\mathrm{mg} / \mathrm{kg} / \mathrm{d}$ ) was calculated as the dose (mg/kg/d)-normalized concentration of $\operatorname{VRCZ}(\mathrm{mg} / \mathrm{L}$ per $\mathrm{mg} / \mathrm{kg}) .{ }^{*} p<0.05$ by the Mann-Whitney $U$-test. NS, not significant. IQR: interquartile range.

was one-third that of the non-LC control group $(6.27 \mathrm{mg} / \mathrm{kg} / \mathrm{d})$, which was a significant difference (Fig. 3).

\section{DISCUSSION}

We examined 6 cases of patients with severe liver cirrhosis (Child-Pugh C) who received oral TDM-based VRCZ therapy. Their daily maintenance doses were in the range of 50-200 mg, which was lower than the standard daily maintenance dose recommended for patients with normal liver function (300-400 mg daily for body weight $>40 \mathrm{~kg}$ per the VRCZ package insert for tablets) and for patients with Child-Pugh classes A and B (150-200mg daily for body weight $>40 \mathrm{~kg})$. $^{10)}$ However, a comparative analysis revealed that the median steady-state VRCZ trough concentrations did not significantly differ between the Child-Pugh $\mathrm{C}$ and control groups (Fig. 3). Furthermore, the median trough concentration for Child-Pugh $\mathrm{C}$ patients was maintained within the desired range of $1.0-5.0 \mathrm{mg} / \mathrm{L}$. Thus, TDM-guided dose optimization could be used to set the maintenance dose in patients with Child-Pugh C so that the VRCZ plasma trough concentration stays within the therapeutic range.

In setting the maintenance dose, one thing to consider is the $\mathrm{C}: \mathrm{D}$ ratio, which is a surrogate marker for $\mathrm{VRCZ}$ clearance. ${ }^{17)}$ As expected, the C:D ratios were higher in the Child-Pugh $\mathrm{C}$ group, implying that $\mathrm{VRCZ}$ clearance was significantly reduced in Child-Pugh $\mathrm{C}$ patients. Moreover, the median daily maintenance dose of VRCZ in the Child-Pugh C group was one-third that of the non-LC group, whereas the median trough levels did not differ. Therefore, a dose reduction to approximately one-third that of the standard maintenance dose would be required in patients with severe liver cirrhosis (i.e., Child-Pugh C). However, the initial dose (loading dose) warrants further investigation.

During the study period, there were seven patients with cirrhosis of Child-Pugh class A $(n=4)$ and $\mathrm{B}(n=3)$ taking VRCZ orally. Among them, one was a child (Child-Pugh class A, 2-years-old), and two more patients with Child-Pugh class $\mathrm{B}$ cirrhosis would be excluded as one was suspected of poor adherence to VRCZ and the other started VRCZ treatment only after $3 \mathrm{~d}$ of liver transplantation and therefore we thought that it would be difficult to classify the Child-Pugh class.

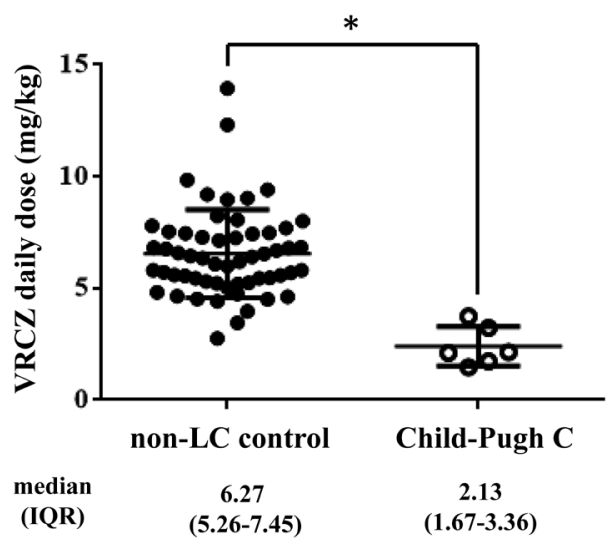

Fig. 3. A Comparison of the Maintenance Dose $(\mathrm{mg} / \mathrm{kg} / \mathrm{d})$ of VRCZ between the Non-LC $(n=56)$ and Child-Pugh C Groups $(n=6)$

Each value represents the daily VRCZ dose $(\mathrm{mg} / \mathrm{kg})$ after reaching steady state. ${ }^{*} p<0.05$ by the Mann-Whitney $U$-test. NS, not significant. IQR: interquartile range.

Moreover, the dose regimen of VRCZ to treat patients with Child-Pugh classes A and B is already established (as stated in VRCZ package insert). Owing to these reasons, we did not analyze and compare Child-Pugh class A/B with Child-Pugh class C group.

We considered that one of the factors affecting VRCZ pharmacokinetics is high inflammatory status. As active infections lead to elevated systemic inflammatory response, CRP levels become elevated, thereby raising the levels of pro-inflammatory cytokines such as interleukin-6 (IL-6). ${ }^{22,23)}$ Elevated IL-6 levels reduce the mRNA expression of CYP2C19 by $30-50 \%$ in in vitro human hepatocytes. ${ }^{23)}$ Thus, it can be deduced that the higher the CRP level, the higher the VRCZ plasma trough concentration.

Indeed, a prospective observational study demonstrated that VRCZ metabolism declines during inflammation (reflected by CRP elevation), resulting in relatively high VRCZ plasma concentrations. ${ }^{24)}$ However, a study on fulminant hepatic failure patients revealed that the CRP elevation merits only slight consideration. ${ }^{25)}$ CRP and IL-6 are produced exclusively by hepatocytes. In patients with severe liver cirrhosis, inflammatory cytokines and CRP would not be significantly elevated, even in those who suffer from infection and inflammation. ${ }^{26}$ ) 
In the present study, the fact that the baseline CRP levels did not significantly differ between the experimental and control groups (Table 3) suggests that the patients' inflammatory statuses were not different (i.e., not extremely high) at the initiation of VRCZ therapy.

Renal replacement therapy, such as hemodialysis (HD) and continuous renal replacement therapy (CRRT), or plasma exchange (PE) potentially affect the pharmacokinetics of various drugs, especially hydrophilic drugs. However, VRCZ is hydrophobic, so it was postulated that no dose adjustment was needed for patients on renal replacement therapy. ${ }^{9)}$ Moreover, previous studies have shown that the PK of VRCZ is unaffected by HD, CRRT, and PE. ${ }^{27-29)}$ Thus, the impact of renal replacement therapy or PE on the PK of VRCZ was likely insignificant.

A multicenter retrospective study reported that the concomitant use of glucocorticoids reduces plasma VRCZ levels, and the concomitant use of PPIs increases plasma VRCZ levels. ${ }^{17)}$ We evaluated the impact of the concomitant use of glucocorticoids and PPIs but could not determine the significance of their influence on VRCZ plasma concentrations. One possible explanation is that the dosage of glucocorticoids (taken by 2 out of 6 patients) was relatively low (less than $5.0 \mathrm{mg} / \mathrm{d}$ prednisolone; Table 2). In addition, the majority (3 of 6) patients on concomitant PPIs were on rabeprazole (Table 2), which likely has the weakest impact on CYP activity.

Nevertheless, our study had several limitations. First, the genetic polymorphism of CYP2C19, a major VRCZ-metabolizing enzyme in liver microsomes, was not determined. Approximately $20 \%$ of the Japanese population are CYP2C19 poor metabolizers (PMs). ${ }^{30)}$ In a previous study, PMs had a median C:D ratio of $0.78(\mathrm{mg} / \mathrm{L}$ per $\mathrm{mg} / \mathrm{kg} ; n=6)$ that ranged from 0.43 to $1.29 .{ }^{31)}$ In the present study, the $\mathrm{C}: \mathrm{D}$ ratio obtained in Child-Pugh C patients was estimated at $1.32(\mathrm{mg} / \mathrm{L}$ per $\mathrm{mg} / \mathrm{kg} / \mathrm{d}$ ), ranging from 0.71 to 1.61 , which was equal to or higher than that reported in PMs. Therefore, the impact of the genetic polymorphism appeared to be inconsequential compared to that of severe liver cirrhosis. Second, this is a singlecenter, retrospective study, and the number of cases analyzed in the Child-Pugh $\mathrm{C}$ group was only 6. For detailed dosage regimens that include a starting dose (i.e., loading dose), a controlled-prospective study is warranted.

In conclusion, our results suggest that the oral maintenance dose of VRCZ should be reduced to approximately one-third that of the standard dose to attain the optimal steady-state plasma trough concentrations in patients with Child-Pugh $\mathrm{C}$ liver cirrhosis. That is, the dosage reduction required for Child-Pugh $\mathrm{C}$ is greater than that recommended for ChildPugh classes A and B. This information, together with TDM, will prevent adverse drug reactions, increase the efficacy of VRCZ and contribute to providing optimal dosage regimens for patients with severe hepatic impairment (i.e., Child-Pugh C), especially for those awaiting liver transplantation.

Conflict of Interest The authors declare no conflict of interest.

\section{REFERENCES}

1) Espinel-Ingroff A. In vitro activity of the new triazole voriconazole (UK-109,496) against opportunistic filamentous and dimorphic fungi and common and emerging yeast pathogens. J. Clin. Microbiol., 36, 198-202 (1998).

2) Karthaus M. Prophylaxis and treatment of invasive aspergillosis with voriconazole, posaconazole and caspofungin-review of the literture. Eur. J. Med. Res., 16, 145-152 (2011).

3) Lazarus HM, Blumer JL, Yanovich S, Schlamm H, Romero A. Safety and pharmacokinetics of oral voriconazole in patients at risk of fungal infection: a dose escalation study. J. Clin. Pharmacol., 42, 395-402 (2002).

4) Saravolatz LD, Johnson LB, Kauffman CA. Voriconazole: a new triazole antifungal agent. Clin. Infect. Dis., 36, 630-637 (2003).

5) Matsumoto $K$, Ikawa $K$, Abematsu $K$, Fukunaga $N$, Nishida $K$, Fukamizu T, Shimodozono Y, Morikawa N, Takeda Y, Yamada K. Correlation between voriconazole trough plasma concentration and hepatotoxicity in patients with different CYP2C19 genotypes. Int. J. Antimicrob. Agents, 34, 91-94 (2009).

6) Laverdiere M, Bow EJ, Rotstein C, Autmizguine J, Broady R, Garber G, Haider S, Hussaini T, Husain S, Ovetchkine P, Seki JT, Théorêt Y. Therapeutic drug monitoring for triazoles: A needs assessment review and recommendations from a Canadian perspective. Can. J. Infect. Dis. Med. Microbiol., 25, 327-343 (2014).

7) Hamada Y, Seto Y, Yago K, Kuroyama M. Investigation and threshold of optimum blood concentration of voriconazole: a descriptive statistical meta-analysis. J. Infect. Chemother., 18, 501-507 (2012).

8) Ueda K, Nannya Y, Kumano K, Hangaishi A, Takahashi T, Imai Y, Kurokawa M. Monitoring trough concentration of voriconazole is important to ensure successful antifungal therapy and to avoid hepatic damage in patients with hematological disorders. Int. J. Hematol., 89, 592-599 (2009)

9) Hamada Y, Tokimatsu I, Mikamo H, Kimura M, Seki M, Takakura S, Ohmagari N, Takahashi Y, Kasahara K, Matsumoto K, Okada K, Igarashi M, Kobayashi M, Mochizuki T, Nishi Y, Tanigawara Y, Kimura T, Takesue Y. Practice guidelines for therapeutic drug monitoring of voriconazole: a consensus review of the Japanese Society of Chemotherapy and the Japanese Society of Therapeutic Drug Monitoring. J. Infect. Chemother., 19, 381-392 (2013).

10) "VFEND prescriving information for voriconazole tablet, film coated.” 〈http://labeling.pfizer.com/ShowLabeling.aspx?id=618; 2017〉, cited 11 December, 2017.

11) Weiler S, Zoller H, Graziadei I, Vogel W, Bellmann-Weiler R, Joannidis M, Bellmann R. Altered pharmacokinetics of voriconazole in a patient with liver cirrhosis. Antimicrob. Agents Chemother, 51, 3459-3460 (2007).

12) Balogh J, Burroughs SG, Boktour M, Patel S, Saharia A, Ochoa RA, McFadden R, Victor DW, Ankoma-Sey V, Galati J, Monsour HP Jr, Fainstein VF, Li XC, Grimes KA, Gaber AO, Aloia T, Ghobrial RM. Efficacy and cost-effectiveness of voriconazole prophylaxis for prevention of invasive aspergillosis in high-risk liver transplant recipients. Liver Transpl., 22, 163-170 (2016).

13) Jeurissen S, Vogelaers D, Sermijn E, Van Dycke K, Geerts A, Van Vlierberghe H, Colle I. Invasive aspergillosis in patients with cirrhosis, a case report and review of the last 10 years. Acta Clin. Belg., 68, 368-375 (2013).

14) Patterson TF, Thompson GR III, Denning DW, Fishman JA, Hadley S, Herbrecht R, Kontoyiannis DP, Marr KA, Morrison VA, Nguyen MH, Segal BH, Steinbach WJ, Stevens DA, Walsh TJ, Wingard JR, Young JAH, Bennett JE. Practice guidelines for the diagnosis and management of Aspergillosis: 2016 update by the Infectious Diseases Society of America. Clin. Infect. Dis., 63, e1-e60 (2016).

15) Barchiesi F, Mazzocato S, Mazzanti S, Gesuita R, Skrami E, Fiorentini A, Singh N. Invasive Aspergillosis in liver transplant recipients: epidemiology, clinical characteristics, treatment, and outcomes in 116 cases. Liver Transpl., 21, 204-212 (2015).

16) Dolton MJ, Ray JE, Chen SC, Ng K, Pont LG, McLachlan AJ. Multicenter study of voriconazole pharmacokinetics and therapeutic drug monitoring. Antimicrob. Agents Chemother., 56, 4793-4799 
(2012).

17) Dote S, Sawai M, Nozaki A, Naruhashi K, Kobayashi Y, Nakanishi $\mathrm{H}$. A retrospective analysis of patient-specific factors on voriconazole clearance. J. Pharm. Health Care Sci., 2, 10 (2016).

18) Qi F, Zhu L, Li N, Ge T, Xu G, Liao S. Influence of different proton pump inhibitors on the pharmacokinetics of voriconazole. Int. J. Antimicrob. Agents, 49, 403-409 (2017).

19) Niece KL, Boyd NK, Akers KS. In vitro study of the variable effects of proton pump inhibitors on voriconazole. Antimicrob. Agents Chemother., 59, 5548-5554 (2015).

20) Cojutti P, Candoni A, Forghieri F, Isola M, Zannier ME, Bigliardi S, Luppi M, Fanin R, Pea F. Variability of voriconazole trough levels in haematological patients: influence of comedications with cytochrome P450 (CYP) inhibitors and/or with CYP inhibitors plus CYP inducers. Basic Clin. Pharmacol. Toxicol., 118, 474-479 (2016).

21) Gage R, Stopher DA. A rapid HPLC assay for voriconazole in human plasma. J. Pharm. Biomed. Sci., 17, 1449-1453 (1998).

22) Papp M, Vitalis Z, Altorjay I, Tornai I, Udvardy M, Harsfalvi J, Vida A, Kappelmayer J, Lakatos PL, Antal-Szalmas P. Acute phase proteins in the diagnosis and prediction of cirrhosis associated bacterial infections. Liver, 32, 603-611 (2012).

23) Aitken AE, Morgan ET. Gene-specific effects of inflammatory cytokines on cytochrome P450 2C, 2B6 and 3A4 mRNA levels in human hepatocytes. Drug Metab. Dispos., 35, 1687-1693 (2007).

24) Veringa A, ter Avest M, Span LFR, van den Heuvel ER, Touw DJ, Zijlstra JG, Kosterink JGW, van der Werf TS, Alffenaar JWC. Voriconazole metabolism is influenced by severe inflammation: a prospective study. J. Antimicrob. Chemother., 72, 261-267 (2017).

25) da Silva Silvestre JP, da Cruz Coelho LM, Póvoa PMSR. Impact of fulminant hepatic failure in C-reactive protein? J. Crit. Care, 25, 657.e7-657.e12 (2010).

26) Lelubre C, Anselin S, Boudjeltia KZ, Biston P, Piagnerelli M. Interpretation of $\mathrm{C}$-reactive protein concentrations in critically ill patients. Biomed. Res. Int., 2013, 124021 (2013).

27) Hafner V, Czock D, Burhenne J, Riedel KD, Bommer J, Mikus G, Machleidt C, Weinreich T, Haefeli WE. Pharmacokinetics of sulfobutylether-beta-cyclodextrin and voriconazole in patients with end-stage renal failure during treatment with two hemodialysis systems and hemodiafiltration. Antimicrob. Agents Chemother., 54, 2596-2602 (2010).

28) Kiser TH, Fish DN, Aquilante CL, Rower JE, Wempe MF, MacLaren R, Teitelbaum I. Evaluation of sulfobutylether- $\beta$-cyclodextrin (SBECD) accumulation and voriconazole pharmacokinetics in critically ill patients undergoing continuous renal replacement therapy. Crit. Care, 19, 32 (2015)

29) Spriet I, Brüggemann RJM, Annaert P, Meersseman P, Van Wijngaerden E, Lagrou K, Willems L. Pharmacokinetic profile of voriconazole in a critically ill patient on therapeutic plasma exchange. Ther. Drug Monit., 35, 141-143 (2013).

30) Mizutani T. PM frequencies of major CYPs in Asians and Caucasians. Drug Metab. Rev., 35, 99-106 (2003).

31) Yamada T, Mino Y, Yagi T, Naito T, Kawakami J. Saturated metabolism of voriconazole $N$-oxidation resulting in nonlinearity of pharmacokinetics of voriconazole at clinical doses. Biol. Pharm. Bull., 38, 1496-1503 (2015). 